YOUNG CHILDREN'S TRUST IN THE FALSE TESTIMONY OF INGROUP VERSUS

\title{
OUTGROUP SPEAKERS
}

$$
\text { Kyla McDonald }
$$

Bachelor of Science honours, Trent University, 2011

A thesis presented to Ryerson University

In partial fulfillment for the degree of

Master of Arts

In the program of Psychology

Toronto, Ontario, Canada

(C) Kyla Patricia McDonald, 2013 
Author's Declaration for Electronic Submission of a Thesis

I hereby declare that I am the sole author of this thesis. This is a true copy of the thesis, including any required final revisions, as accepted by my examiners.

I authorize Ryerson University to lend this thesis to other institutions or individuals for the purpose of scholarly research

I further authorize Ryerson University to reproduce this thesis by photocopying or by other means, in total or in part, at the request of other institutions or individuals for the purpose of scholarly research.

I understand that my thesis may be made electronically available to the public. 


\begin{abstract}
The present research explores whether young children display different levels of trust in the testimony of speakers from their own social group (ingroups) versus another social group (outgroups). Three- and 4-year-old children watched through a window as an adult hid a toy in one of three containers. The adult then told the child that she had put the toy in a container different from the one where it was actually hidden (i.e., false testimony). At the end the child was asked to retrieve the toy. The adult was either a Caucasian, native English speaker (ingroup) or an Asian English speaker with a noticeable foreign accent (outgroup). Four-year-old children were credulous to the false testimony of the ingroup speaker, despite their firsthand observations, but were skeptical and relied on their own observations when the false testimony was provided by the outgroup speaker. In contrast, 3-year-old children remained credulous to the false testimony of both speakers. These findings were discussed in relation to children's early preferences for ingroup members and the developmental shift in skepticism displayed by 4-yearold, but not 3-year-old children. This research will make a unique contribution to our understanding of how young children selectively learn from other people and why they remain credulous to some speakers, but not to others.
\end{abstract}

Key words: trust, testimony, firsthand observations, speaker social category, ingroup, outgroup 


\section{Acknowledgements}

Many thanks are extended to the child participants and their parents, and to the research assistants in the Early Childhood Cognition Lab for all their gracious support and encouragement throughout the data collection process. In addition, thank you to both Dr. Margaret Moulson and Dr. Stephen Want for agreeing to be on this thesis committee and for providing constructive criticism and valuable advice along the way. Finally, my deepest gratitude and appreciation is given to Dr. Lili Ma for being an inspiring mentor and teacher. Thank you for your patience and guidance. 


\section{Table of Contents}

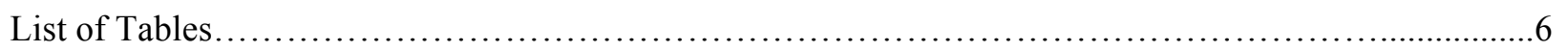

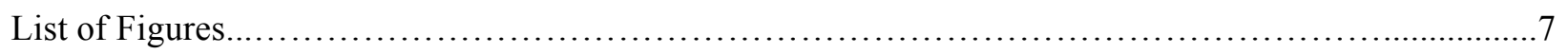

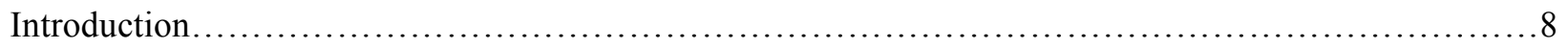

Factors that Influence Children's Trust in the Testimony of Others...........................

Speaker Past Reliability.....................................................9

Speaker Knowledge-State.................................................14

Bystander Cues and Group Consensus........................................... 15

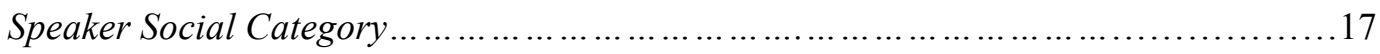

Gender....................................................................... 19

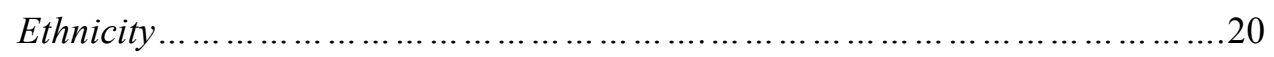

Language and Accent..............................................21

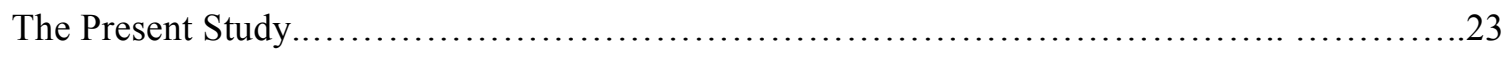

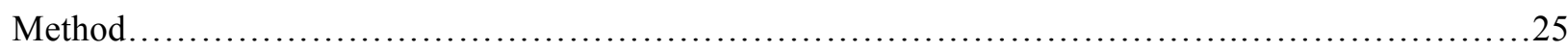

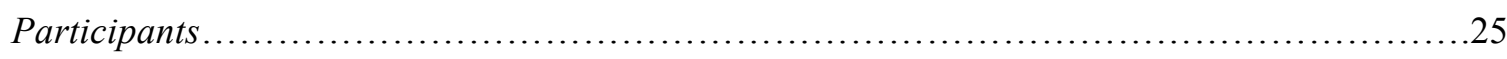

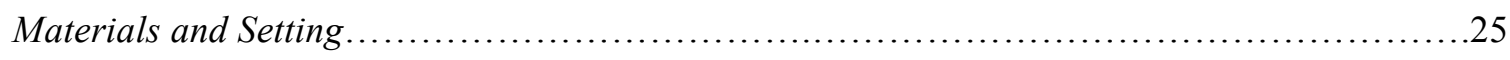

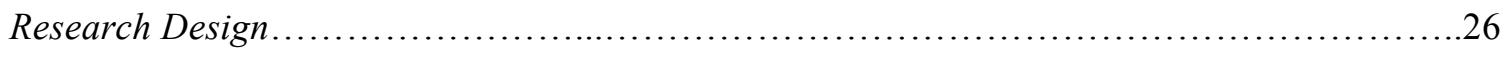

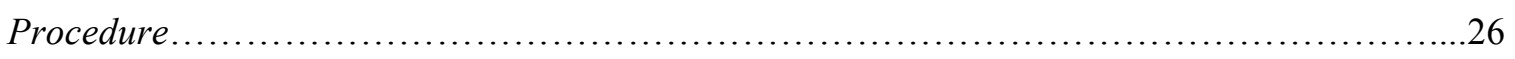

Coding and Reliability.......................................................... 28

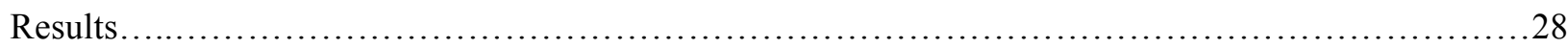

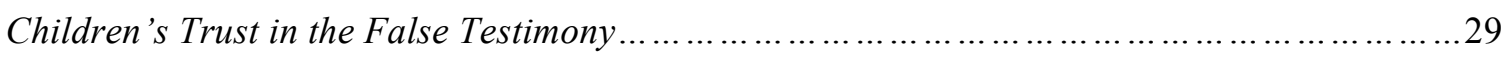

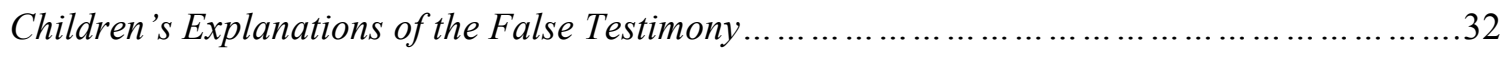

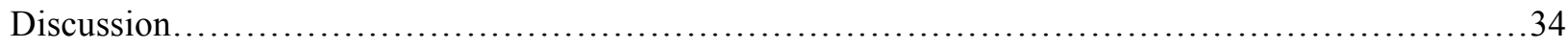

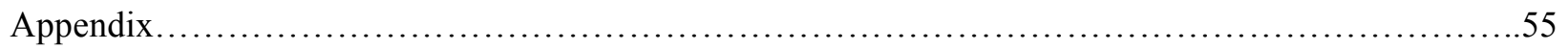




\section{List of Tables}

Table 1. Group Descriptors by Condition and Age......................................29

Table 2. Logistic Regression with Age in Months and Exposure as Predictors..................31

Table 3. Children's Responses to the Memory-Check Questions by Condition and Age.........32 


\section{List of Figures}

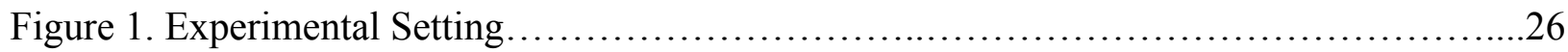

Figure 2. Percent of Children Who Were Credulous or Skeptical to the False Testimony..........30

Figure 3. Percent of Children Who Explained the False Testimony as Trick or Mistake.........33 
Young Children's Trust in the False Testimony of Ingroup Versus Outgroup Speakers

\section{Introduction}

It is important to explore the development of children's trust in others to further understand how children learn and from whom they choose to learn most effectively. Trust in others is critical to knowledge acquisition and development (e.g., Harris, 2007; Harris \& Koenig, 2006; Harris, Pasquini, Duke, Asscher, \& Pons, 2006). Children depend on the testimony of others for information about the world that they themselves cannot attain through direct sensing. For example, children cannot directly witness events during medieval times or observe exactly where Neptune is located through the naked eye. Harris and Koenig (2006) define testimony as a statement provided by an informant that does not require reliable first-hand evidence or an oath to back it up. Clement, Koenig, and Harris (2004) outline three important functions that trust in the testimony of others provides: (1) transfer of family narratives along the family line, (2) learning historical facts about one's country and the world, and (3) learning scientific facts. Thus, trust in the testimony of others plays a culturally important role in transferring information from generation to generation (Tomasello, 2008). Throughout development, children have to learn to assess the testimony of others with a critical eye, as they may often be provided with false information.

Unfortunately, it is not uncommon to receive false testimony from an informant, whether it is unintentional (e.g., mistaken directions) or intentional (e.g., supernatural entities such as Santa Claus) (Clement et al., 2004; Harris, 2007). In early life, children receive vast amounts of new information from several sources, and are thus required to selectively attend to which sources of information are credible and which are not. This impacts what information they will learn and eventually transfer to others. Studying when and how children begin to take a 
skeptical stance when learning from others is essential to understanding the possible mechanisms underlying cultural transmission. The present research aims to extend the literature on how children learn from others and whom they trust the most, by exploring whether they are skeptical of the false testimony of ingroup members versus outgroup members.

\section{Factors that Influence Children's Trust in the Testimony of Others}

Even young children have a sense that all sources are not equal (Harris \& Koenig, 2006; Koenig, Clement, \& Harris, 2004; Ma \& Ganea, 2010; Sabbagh \& Baldwin, 2001). This suggests that children have the ability to skeptically judge a speaker's testimony. A few factors appear to influence children's reliance on the testimony of others when they are weighing information from more than one source: (1) the past reliability of speakers (Koenig, et al., 2004; Ma \& Ganea, 2010), (2) the knowledge-state of speakers (Sabbagh \& Baldwin, 2001), (3) bystander cues and group consensus (Chen, Harris, \& Corriveau, 2012; Corriveau, Fusaro \& Harris, 2009; Fusaro \& Harris, 2008), and (4) the social category of speakers (e.g., Kinzler, Dupoux, \& Spelker, 2007; Kinzler, Corriveau, \& Harris, 2010).

Speaker past reliability. Throughout childhood, children develop a balance between being credulous to others in order to learn, while also being skeptical to avoid learning false information (Gelman, 2009). This balance can be viewed as adaptive, as learning occurs when one trusts in the source relaying the information. For example, if a child believes a speaker is silly or untrustworthy, it would be unlikely that any information provided by the speaker will be learned, which could potentially shield the child from learning valuable information. In contrast, having a critical eye when receiving new information can allow children to distinguish reliable from unreliable sources. Even young infants display early signs of learning based on the past actions of a speaker, and thus show signs of skepticism in subsequent situations. For example, 
when locating a hidden object, 14-month-old infants selectively follow the eye gaze of informants based on their past reliability, with their eye gaze following reliable informants more often than unreliable ones (Chow, Poulin-Dubois, \& Lewis, 2008). In addition, 16-month-old infants showed sensitivity to word-object violations, by looking reliably longer at speakers that provided inaccurate labels for familiar objects (Koenig \& Echols, 2003). These findings indicate that from early on in development, infants are able to recognize the past accuracy of speakers and respond accordingly.

By preschool years children have developed a robust sensitivity to the past reliability of speakers. Clement and colleagues (2004) examined whether children could track the reliability of a speaker to predict how the speaker would label an object in a subsequent situation. During the task, two puppets labeled a pompom: one puppet labeled it with the correct colour and a second puppet labeled it with an incorrect colour. Children were then asked to predict what colour each puppet would label a new pompom. Results of the study revealed that 4-year-old children anticipated how accurate each puppet would be based on their previous performance, selectively trusting in the more reliable source. In contrast, only half of 3-year-old children made predictions about the informants based on their previous experience, with the other half indiscriminately predicting accuracy for both puppets. There appears to be a developmental shift between 3- and 4-year-olds in their ability to explicitly label a speaker as reliable or not and to use a speaker's past reliability to assess his or her future accuracy (Clement et al., 2004).

Koenig et al. (2004) further explored the circumstances that initiated children's selective trust in others. In their study, two speakers provided labels for familiar objects: one speaker provided the correct labels all the time (e.g., labeling a ball a "ball"), and the other provided the incorrect labels all the time (e.g., labeling a ball a "shoe"). Children were asked to identify 
whether either of the speakers said something wrong. During the test trial, the same speakers were asked to name a novel object. For example, one speaker labeled the object a "mido", and the other labeled it a "toma". Children were then asked what the object was called, having to endorse one of the two speakers' testimonies. Children who correctly identified the unreliable versus the reliable speakers were more likely to subsequently endorse the testimony of the reliable speaker. In Clement et al. (2004), fewer 3-year-olds compared to 4-year-olds demonstrated selective learning based on the puppets' past reliability. Koenig et al. (2004) replicated this finding, but further revealed that 3-year-olds are capable of selective learning based on past reliability when children explicitly identified the speaker as unreliable. The results suggest that categorical judgments about a speaker's past reliability are essential when selectively endorsing a novel testimony in a subsequent situation (Koenig et al., 2004). Koenig and Harris (2005) further revealed that when the experimental paradigm does not apply the use of novel object labeling, no differences exist between 3- and 4-year-olds in explicit judgment labeling and selective learning. For example, because people do not generally label a shoe a "ball" or vice versus, there is the expectation that people are serious and truthful when they provide information. An experimenter that provides an inaccurate label for something as well known as a shoe might not be judged as unreliable, but rather viewed as silly and not serious. Instead, when speakers were explicit and claimed ignorance (e.g., I don't know what this is called), 3-year-old children were as capable as 4-year-old children at: (1) identifying the reliable versus unreliable speaker, and (2) subsequently endorsing the reliable speaker's testimony, eliminating the previously observed age difference (Koenig \& Harris, 2005).

The overall results indicate that young children have the ability to track and monitor the accuracy of a speaker from one situation to the next (Koenig \& Harris, 2005). To further support 
these results, Pasquini, Corriveau, Koenig, and Harris (2007) used a similar paradigm to consistently reveal that 3- and 4-year-olds monitor speaker accuracy when endorsing object labels in subsequent situation, choosing to endorse the novel label provided by the previously correct speaker. In addition, Birch, Vauthier, and Bloom (2008) found that both 3- and 4-yearolds preferred to learn object names and functions from previously reliable speakers rather than from previously unreliable speakers.

The previous studies all involved informants, speakers, or "puppets" that were unfamiliar to the child, thus it is possible that the results may have been different with familiar speakers. However, there is evidence that familiarity of the speakers only serves to support the previous findings, with 4- to 5-year-old children displaying increased trust in familiar speakers that were previously reliable, and consequently decreased trust in familiar speakers that were previously unreliable (Corriveau \& Harris, 2009). Taken together, previous studies demonstrate that regardless of speaker familiarity, young children can accurately identify reliable versus unreliable speakers, and use this knowledge to decide which testimony to endorse in a subsequent situation. It is less clear, however, how children deal with the testimony of an informant when they also have direct access to what is true and what is not (i.e., direct observation), in contrast to learning object labels that cannot be verified.

By the age of 3, children begin to recognize the link between seeing and knowing (Pratt \& Bryant, 1990). This ability allows children to logically connect the knowledge of a box's contents to the person that has looked inside the box, but not to someone who has only touched the outside of the box (Pratt \& Bryant, 1990). A child's understanding that other individuals can have a mental representation that does not correspond with reality is commonly referred to as false-belief understanding (Flavell, 2004). Typically developing children acquire false-belief 
understanding by the age of 4 or 5 years (Astington \& Jenkins, 1999; Baron-Cohen, 1985; Flavell, 2004; Leslie, 1987; Wellman, 1990; Wimmer \& Perner 1983; Wellman, Cross \& Watson, 2002), although there is a lot of individual variability (Baron-Cohen, 1985; Wellman, 1990). In contrast, less research has explored children's judgments of the false testimony of a speaker, when both the child and the speaker have access to the same information (or knowledge).

Ma and Ganea (2010) explored this question to further understand how children learn from others in a problem-solving scenario where the testimony of a speaker conflicts with children's direct observations. Three- to 5-year-old children were placed in a real-life situation, where they had to rely on either their firsthand observations or the testimony of a speaker to solve a problem. In their study, Ma and Ganea (2010) found that 3-year-olds and some 4-yearolds were credulous and relied on an adult's false testimony about the hiding location of an object, despite their firsthand observations of where the object was actually hidden. Five-yearold children were skeptical and relied on their firsthand observations, ignoring the speaker's false testimony. In relation to false-belief understanding, it appears that once children are confident in what they observe to be true (at 5 years of age), they can then reliably assess others' mental representations and understand that what they know to be true and what others know to be true may or may not differ (Astington \& Jenkins, 1999; Baron-Cohen, et al., 1985; Flavell, 2004; Leslie, 1987; Wellman, 1990; Wimmer \& Perner 1983). Results in a subsequent study indicated that when 3- and 4-year-old children were given a positive searching experience based on their own observations, they disregarded the false testimony of the speaker (Ma \& Ganea, 2010). Also, in accordance with previous research, when children were exposed to a single situation in which they were provided with false information from a speaker, this exposure led them to 
disregard the speaker's false testimony in a subsequent situation and rely on their own observations (Ma \& Ganea, 2010).

To summarize, although 3- to 4-year-old children appear to be credulous to the misinformation provided by a speaker despite their own firsthand observations, a single breach of trust (e.g., speaker past accuracy) can often ignite a more skeptical view of the speaker. Children, like adults, appear to learn from others and modify their outlook of a speaker based on how reliable that speaker was in the past.

Speaker knowledge-state. In addition to the past reliability of speakers, children appear to learn from others based on inferences made about a speaker's knowledge-state. For example, Three- and 4-year-old children choose to learn from speakers who are explicitly labeled as being knowledgeable, over those labeled as ignorant (Esbensen, Taylor, \& Stoess, 1997; Sabbagh \& Baldwin, 2001). In Sabbagh and Baldwin (2001), for example, two speakers taught children novel words: one speaker was labeled as knowledgeable about the words expressing that they "knew" the word and the other was identified as ignorant about the words expressing that they “didn't know" the words. In general children learned more reliably from the knowledgeable speaker than from the ignorant speaker. In addition, more 4-year-old than 3-year-old children made inferences to determine a speaker's knowledge-state, and did not just rely on speaker hesitation. For example, in 4-year-old children, learning was only avoided when a speaker's hesitation about the words was viewed as a sign of ignorance (Sabbagh \& Baldwin, 2001). If children did not view hesitation as a sign of ignorance, children still learned from that speaker reliably. Three-year-old children did not demonstrate this pattern, assuming that any speaker hesitation was a sign of ignorance (Sabbagh \& Baldwin, 2001). 
In addition, research findings reveal that older children are more skeptical of how a speaker becomes knowledgeable about the object or word initially (Einav \& Robinson, 2011). Four- and 5-year-old children preferred to learn from speakers that previously provided accurate information without any help (unaided) to a speaker that previously sought assistance from another person. Children may view an individual who does not require assistance to be more knowledgeable, or possibly smarter. This assumption may create a "halo" around the unaided speaker, making them more appealing to learn from. Three-year-old children did not display this pattern of reasoning, learning from both speakers indiscriminately.

In conclusion, it appears that 4- and 5-year-old children display selective trust outside of simply monitoring the past accuracy of an informant (Einav \& Robin, 2011; Sabbagh \& Baldwin, 2001). For example, they choose to learn from speakers that claim they are knowledgeable without obtaining any prior experiences with those individuals. In addition, if a speaker typically requires assistance in the past to provide correct information, older children choose not to learn from this speaker in a subsequent situation. These cues help children selectively decide who may be a reliable source, which consequently influences their trust in his or her testimony.

Bystander cues and group consensus. As previously explored, children assess several behavioural cues (e.g., mislabeling familiar objects, or seeking assistance to solve a problem) when making judgments about a speaker's credibility. Recent findings also reveal that children pay attention to outside sources and bystanders' assessments of others when they have no background information on the speaker (Fusaro \& Harris, 2008).

Past research has shown that infants and young children monitor the non-verbal reactions of bystanders when they are learning about the world (Campos, 1980; Feinman \& Lewis, 1983; 
Mumme, Fernald \& Herra, 1996; Tomasello \& Barton, 1994). In light of these findings, Fusaro and Harris (2008) examined whether 4-year-old children would selectively endorse the testimony of informants who previously received nonverbal bystander assent (e.g., head nod or smile) versus nonverbal bystander dissent (headshake or frown). They found that young children chose to endorse claims provided by informants who had received bystander assent. The observed effect appeared to be mediated by children's overall ability to understand mental states, with more advanced children displaying greater preference for the speaker who received bystander assent. These results demonstrate that children pay attention to the nonverbal cues of third parties when assessing informant reliability. Moreover, young children not only monitor bystander nonverbal cues but also attend to group consensus in their selective learning.

Corriveau and colleagues (2009) measured whether 3- and 4-year-old children endorse novel object labels based on whether the potential referent of the label was identified by a group consensus. During the pretest phase, children were provided a novel object name (e.g., modi) and asked which object it represented, while watching three adults (i.e., the nondissenters) pointing to one object and one adult (i.e., the dissenter) pointing to an alternate object. In line with Fusaro and Harris (2008), children systematically preferred to select the referent that was identified by the group consensus. More interestingly, this pattern prevailed in the test phase when there were only two informants - one of the three nondissenters and the original dissenter, in that children remained skeptical of the dissenter and preferred to endorse the testimony of the nondissenter (Corriveau et al., 2009).

Chen and colleagues (2012) further explored children's use of group consensus as a function of group composition (e.g., all ingroups from their own race, or both ingroups and outgroups). Following the paradigm of Corriveau et al. (2009), during the pretest phase, 3- and 
4-year-olds were asked to determine the referent of a novel object label. Three informants (i.e., the nondissenters) pointed to one object, and one informant (i.e., the dissenter) pointed to an alternate object. During the test phase, children were presented with one of the three nondissenters and the original dissenter as potential informants in a word learning task. They were also interviewed about how sensitive they were to the group composition. In line with previous findings, during the pretest phase children preferred the object endorsed by the group consensus, regardless of group composition. More interestingly, during the test phase, children in the "all ingroup" condition preferred to learn from the informant previously in the group consensus. However, this preference was not evident in children in the "mixed" condition, where the group was comprised of both ingroup and outgroup members. It is important to note that children explicitly recognized the differences between the ingroups and outgroups with respect to both race and facial characteristics, and identified with the members of their own race (Chen et al., 2012).

To summarize, young children use non-verbal cues that reflect group consensus (e.g., bystander assent) to guide their selective learning from others, and favor the information from nondissenters rather than a dissenter. However, the effect of group consensus is weaker when a member of the consensus belongs to the child's social outgroup, and thus suggests that ethnicity influences children's trust in others.

Speaker social category. As previously explored, factors such as the past reliability and knowledge-state of speakers, as well as bystander non-verbal cues and group consensus appear to influence children's selective trust in the testimony of others. It is possible that speaker social category may also influence children's selective learning from others. 
Previous research highlights the importance of studying children's early reasoning about social group membership, and the role ingroup biases can play in the development of children's outward displays of prejudice (Arthur, Bigler, Liben, Gelman, \& Roble, year; Verkuyten, 2008). An "ingroup" bias is commonly defined as having more positive feelings for a group that an individual identifies with, such as one's family, ethnic group, gender, age, or even sports team (Files, Casey, \& Oleson, 2010). An individual may explicitly state these superior feelings for their ingroups, or the feelings may be held unknowingly. Having these positive feelings toward ingroups can often create negative feelings for outgroup members (Files et al., 2010). Many studies suggest that when adults are placed in differing groups based on meaningless criteria (e.g., coin toss, lottery, etc.), they appear to quickly develop a bias towards their ingroups (Billig \& Tajfel, 1973; Locksley, Oritz, \& Hepburn, 1980).

Children display similar forms of ingroup biases early on in life and appear to focus on the familiarity of a speaker (e.g., whether or not the speaker is a friend or a stranger) when listening to simple statements that cannot directly be verified (Ackerman, 1983). They tend to make ingroup judgments based on superficial preferences for the speaker, even if the alternative source may be more reliable. For example, Ackerman (1983) found that 6-year-old children tended to trust a neighbour's description of an account over a newspaper's. These findings suggest that children assume knowledge in people that they have preferences for and turn to these individuals for information over reputable sources. Thus, children may display ingroup biases and make inferences about speaker knowledge-state when judging others as information sources.

Research has explored young children's preferences for others of their own gender (Shutts et al., 2010; Ma \& Woolley, 2012; Maccoby, 1988) and ethnic group (Gelman, 1997; 
Kelly et al., 2005; Shutts et al., 2010) when learning novel information. Social judgments also appear to be made based on a speaker's spoken language (Kinzler, Corriveau, \& Harris, 2010; Ackerman, 1983; Akhtar, Menjivar, Hoicka, \& Sabbagh, 2012). The following section will explore childrens' early preferences for ingroup members.

Gender. During childhood, the physical and gender-related schemas shaped by culture appear to play an important role in the identification of one's own gender (Picariello, Greenberg, \& Pillemer, 1990). Children begin to learn about the biological attributes of each gender during the first year of life (Signorella, Bigler, \& Liben, 1993; Tennenbaum, Hill, Joseph, \& Roche, 2010). During the preschool years, schemas are formed and influence how children learn from cues about what belongs to each gender (Picariello et al., 1990). For example, a child may assume that because another child is wearing pink, that child is a girl (Boyatzis \& Varghese, 1993; Picariello et al., 1990). Gender then becomes a source for making social attributions, stereotypes, and judgments about people (Maccoby, 1988).

In early infancy, infants display selective preferences for others based on the gender of their primary caregivers (Quinn, Yahr, Kuhn, Slater, \& Pascalis, 2002). For example, in a preferential looking task, infants 3 - to - 4 months raised primarily by a female caregiver directed more attention towards female than male faces. However, children raised primarily by a male caregiver displayed preferential looking towards male rather than female faces (Quinn et al., 2002). During early childhood, gender-based preferences become more observable. Threeyear-old children prefer novel objects that are endorsed by people of their own gender (Shutts, et al., 2010). Four- and 6-year old children also demonstrate a similar ingroup bias when learning about the functions of novel objects from the testimony of other people, prefering to learn from individuals of their own gender (Ma \& Woolley, 2013). 
Ethnicity. Ethnicity is important to both adults and children when forming social judgments. This has been observed throughout history in unfortunate circumstances. The preferences observed for one's own race appear to develop early on in life.

Looking-time studies have shown that 3-month-old Caucasian (Kelly et al., 2005), African (Bar-Haim, Ziv, Lamy, \& Hodes, 2006), and Chinese (Kelly et al., 2007) infants prefer to look at faces of their own race to faces of a different race. In contrast, Kinzler and Spelke (2011) found that 6-month-old White infants did not display ingroup preferences when accepting toys from a White versus a Black individual. Additionally, in a subsequent study using a "giving game", 2.5- to 3-year-old children gave presents to Black and White children equally. Some researchers suggest that an explicit ingroup bias of ethnicity only begins to fully emerge in the late preschool years (Furby \& Kircher, 1971), thus explaining the mixed findings just mentioned above. For example, there are no distinct patterns of racial ingroup biases observed in 3-year-old children, but 5-year-old White children display a robust ingroup bias over Black children (Furby \& Kircher, 1971). Supporting this finding, when 5-to 6-year-old White children were asked explicitly who they predicted an infant would prefer to receive a toy from (a Black or a White individual), a strong preference was displayed for the White individual (Kinzler \& Spelke, 2011).

It appears that there is a progression for children to prefer their own ethnic group when they embark into the school years. It is interesting to note that children display an early preference to look toward the faces of one's own race (Bar-Haim et al. 2006; Kelly et al. 2005; Kelly et al. 2007), but show more equal preferences in early childhood through behavioural displays such as gift-giving (Kinzler, \& Spelke, 2011), and then later display ethnicity-based ingroup biases in the early school years (Furby \& Kurcher, 1971; Shutts et al., 2010). This may reflect differences in experimental procedures (e.g., looking time data versus behavioural 
paradigms such as gift giving). For example, children may hold early preferences, but these preferences may not be displayed within their early behaviours, and may suggest that earlier looking-time studies explore a different preference, such as a preference for those that are familiar to the child. However, these results may indicate other social factors are creating a stronger bias in early childhood other than race (e.g., spoken language, or accent), which manifests itself into the later ingroup ethnicity biases. Language may appear to be a more prominent guiding cue for who is in one's social group and who is not in early childhood, regardless of racial differences.

Language and accent. Earlier studies exploring children's preferences for ethnic groups revealed that young children do not display an explicit ingroup bias for members of their own race until about 5 to 6 years of age. Language, however, does appear to guide children's early categorization of people (Hirschfeld \& Gelman, 1997). For example, children believe that minority-race individuals wearing unfamiliar clothing are more likely to speak a foreign language and belong to a different social group than their own group (Hirschfeld \& Gelman, 1997). An individual's ethnic, social, or national group can be inferred from the accent with which they speak (Labov, 2006). Infants as young as 19 months can recognize familiar words provided by speakers that have foreign dialects (Best, Tyler, Gooding, Orlando, \& Quann, 2009). However, children are unable to learn words from foreign-accented individuals until they are approximately 2.5 to 3 years old (Schmale, Hollich, \& Seifl, 2011), but then are able to make assumptions that people from other cultures may likely speak a different language (Hirschfeld \& Gelman, 1997), suggesting that stereotypes about linguistic relationships to social status and ethnicity can be observed very early in life (Hirschfeld \& Gelman, 1997; Labov, 2006; Schmale et al., 2011). 
Infants and young children display preferences for individuals that speak their native language, or that share their native accent over foreign-accented speakers (Kinzler, et al., 2007; Kinzler et al., 2010: Kinzler \& Spelke, 2011; Moon, Cooper, \& Fifer, 1993; Shutts et al., 2010). Two-day-old newborns demonstrate early preferences for the recordings of strangers speaking their mother's native language over a foreign language (Moon, et al., 1993). Six-month-old infants prefer to play with toys offered by speakers who speak their own language rather than speakers who speak a foreign language (Kinzler et al., 2007), and 10-month-old infants choose to learn the functions of novel objects from the behaviour of native rather than foreign-accented speakers (Kinzler et al., 2010). Three- to 4-year-old children tend to endorse novel words provided by an English speaker over a foreign speaker (Akhtar et al., 2012). Interestingly, only children exposed to more than one language (but who are not fully bilingual) correctly endorse a foreign speaker's label when asked for the label in the foreign language (e.g., "What do you call this in Nordish?"). This result is likely due to the exposed children's metalinguistic awareness and openness to other languages, while not knowing definitively the rules and structures of both languages (Akhtar et al., 2012).

In addition, 4- to 5-year-old children prefer peers with native accents as friends to foreign-accented children, despite understanding both speakers equally well (Kinzler, Shutts, Dejesus, \& Spelke, 2000). In support of the previous prediction that language may override race in influencing children's selective preferences, when presented with pictures matched with voice recordings children choose native-accented, other-race children as friends, over same-raced, foreign accented children (Kinzler et al., 2009). These findings suggest that language plays a superior role to race in determining preferences in early childhood, and likely influence children's trust in others' testimony (Kinzler et al., 2010). 
To date, relatively little is known about whether young children would also show such ingroup biases when evaluating the testimony of others, despite the fact that nowadays children often have to weigh individuals from different social groups as potential sources of information. Kinzler et al. (2010) revealed that 4- to 5-year-old children tend to trust American-accented English speakers over Spanish-accented English speakers when learning new object labels. However, this effect disappeared in a follow-up study when foreign accented speakers labeled objects accurately and native-accented speakers were inaccurate, suggesting that accuracy trumps accent in guiding children's trust (Corriveau, Kinzler, \& Harris 2013).

To summarize, the above findings suggest that children display preferences for individuals that share their gender or speak their native language. In addition, children prefer to endorse the testimony of members of their own gender when learning about the functions of novel objects. It is also clear that children use an individual's spoken language as a prominent guiding cue for making social judgments.

\section{The Present Study}

Previous research has revealed young children's preferences for members of their own race (Bar-Heim, 2006; Kelly et al., 2005; Kelly et al., 2007), and for those that speak their language or share their native accent (Kinzler, et al., 2007; Kinzler et al., 2010: Kinzler \& Spelke, 2011; Moon et al., 1993; Shutts et al., 2010). However, it is unclear whether these preferences translate into how children weigh information from different sources to solve realworld problems. There is no research to date that explores how these social judgments are made when children are provided with false testimony, such as claims that conflict with their own firsthand observations. The present study seeks to fill this gap in the literature. 
More specifically, the present study examines the role of speaker ethnicity in young children's trust in false testimony that contradicts their firsthand observations. A speaker's accent is a reliable cue to his or her ethnicity (Hirschfeld \& Gelman, 1997; Labov, 2006). Researchers have explored children's trust in the testimony of others that speak their native language to those that speak a second language, such as French or Spanish (Akhtar et al., 2012; Kinzler, et al., 2010). However, relatively less is known about how a language outside of the child's second language will influence reliance on a speaker's testimony. It is well known that many children living in America are exposed to the Spanish language early in life (Federal Interagency Forum on Child and Family Statistics, 2010), as are children raised in Canada to the French language (Jared, Cormier, Levy \& Woolley, 2010). Many stereotypes or biases may be present early in life due to the simple immersion or knowledge of these languages within a child's culture. Limited research has explored how children weigh information provided by a speaker with a foreign accent outside of the child's second language, such as English speakers with a noticeable Chinese accent. Native English speakers rate Chinese English speakers' pronunciation as less authentic than native English speakers (Flege, 1988). This may negatively influence children's trust in the testimony of a speaker with this particular accent.

In the present study, 3- and 4-year-old Caucasian, native English speaking monolinguals were placed in a real-life situation, in which they could rely on either their firsthand observations or the testimony of an adult to solve a problem, using the research paradigm of Ma and Ganea (2010). Children watched through a window as an adult hid a toy in one of three containers. The adult then told the child that she had put the toy in a container different from the one where it was actually hidden. This was the false testimony. At the end the child was asked to retrieve the toy. The adult speaker was either a Caucasian, native English speaker (Ingroup condition) or 
a Chinese English speaker with a noticeable accent (Outgroup condition). The question of interest was whether children's trust in the false testimony would vary as a function of the informant's social category.

\section{Method}

\section{Participants}

The final sample consisted of 64 typically developing children who were Caucasian, native English speakers: 32 3-year-olds $(M=42.0$ months, range $=36.8-47.6$ months, 16 females), and 32 4-year-olds $(M=52.3$ months, range $=48.0-58.3$ months, 14 females $)$. Seventeen children were not included in this sample because they were either from a different ethnicity or were bilingual. Thirty-two children participated in the Ingroup condition (16 threeyear-olds and 16 four-year-olds), and 32 in the Outgroup condition (16 three-year-olds and 16 four-year-olds). All children were recruited through the Infant and Child Database at Ryerson University, and were asked to come to the lab to participate.

\section{Materials and Setting}

Three different containers with covers (blue bucket, pink bowl, and yellow box) were each placed on one of three chairs. One of the containers was used as the correct hiding location (C), one as the neutral location $(\mathrm{N})$, and one as the incorrect hiding location based on the false testimony (F). A toy served as the target object. A video camera recorded the child's behaviours and responses throughout the study.

The experiment took place in two rooms - the testing room and the observation room, connected by a one-way window (Figure 1). First, the speaker hid the target object in $\mathrm{C}$ in the testing room, while the child observed in the observation room through the one-way window. 
Immediately after, the speaker walked into the observation room and provided the false testimony about the hiding location of the object to the child.
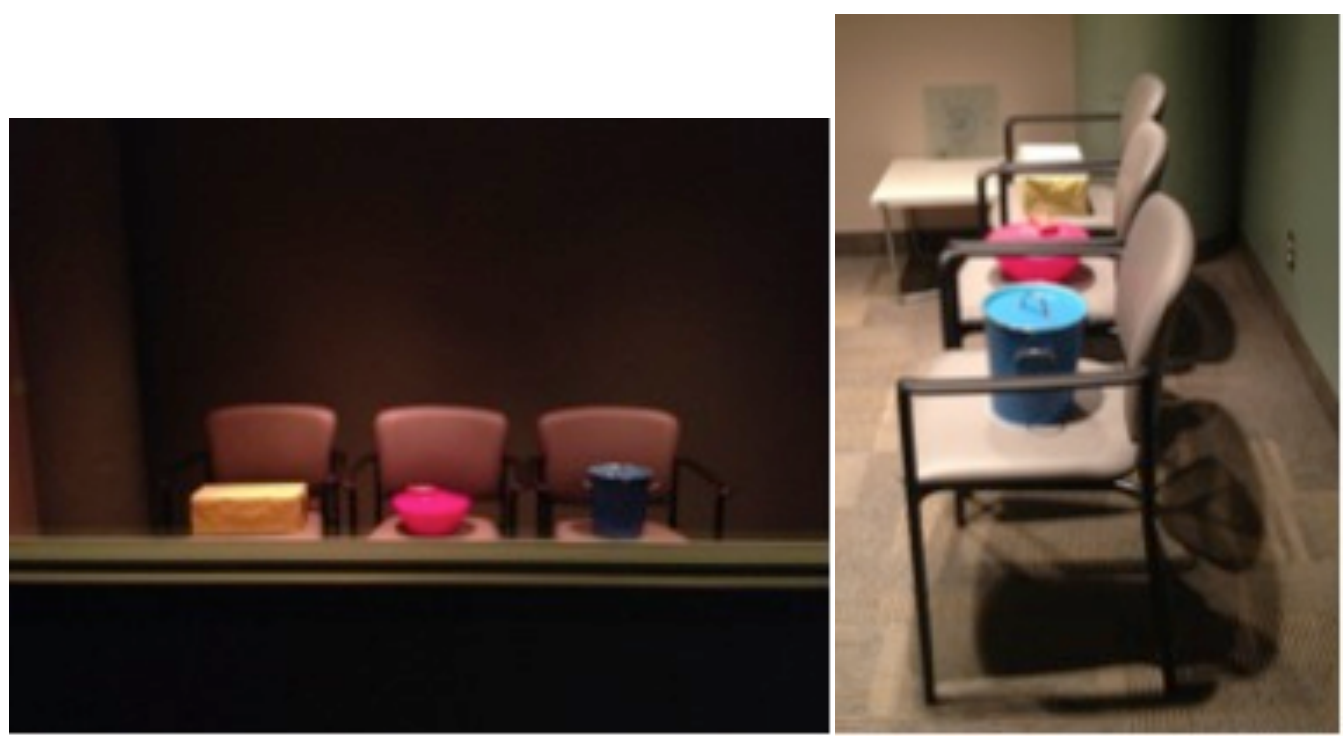

Figure 1. Experimental setting: View from the observation room into the testing room through a one-way window (left) and the testing room (right).

Parents were asked to fill in a demographics questionnaire, which included a measure of their child's everyday exposure to different ethnic groups.

\section{Research Design}

This experiment employed a 2 (condition) x 2 (age) between-subjects design. At each age, children were randomly assigned to one of the two conditions, with the restriction that there were an equal number of girls and boys in each condition.

\section{Procedure}

Modeling after Ma \& Ganea (2010), the parent and the child were directed into a waiting room, where the parent filled in a consent form and a demographics questionnaire while the child played with a Caucasian native English female experimenter (E1). First, E1 made the child feel comfortable within the setting, which was evident through the child's willingness to play with E1 
and leave parent's direct side (e.g., not sitting in parent's lap and openly talking to E1). During this time, another experimenter (E2) was also in the room, but made limited contact with the child, remaining neutral at the computer (e.g., E2 waved hello and turned around to "work").

Ten female experimenters in total performed the role of E2: Six experimenters were Caucasian native English-speakers (ingroup condition), and 4 experimenters were Asian nonnative English-speakers (outgroup condition).

When the child was comfortable, E2 made an excuse to leave, and E1 directed the parent and the child to the testing room (see descriptions under "Materials and Setting"). The experimental procedure with three phases then began.

During the orientation phase, the child was instructed by E1 to label and look inside each container. Once the child confirmed that all three containers were empty, E1 covered each container. The child was then directed into the observation room. E1 asked the child to peer through the window to ensure that he or she could clearly see the containers. Then E1 told the child that E2 was going to put a prize for the child in one of the containers, and that they were going to observe her doing this.

During the test phase, E2 entered the testing room with a prize. She then placed the prize in $\mathrm{C}$ and covered it. While this occurred, in the observation room $\mathrm{E} 1$ asked the child in which container E2 had hidden the prize. E2 then exited the testing room, and entered the observation room excitedly, exclaiming that she had hidden the toy in F: "Here you are! Guess what? I have a prize for you! I just put your prize in the (F)! Can you go find it?" E2 referred to the container in terms of its colour and identity. Both experimenters and the parent waited in the observation room as the child entered the testing room to retrieve the prize from the container of choice. 
During the interview phase, the child was first asked two memory-check questions where E2 put the toy and where E2 said she put the toy, to ensure that he/she remembered the correct hiding location and understood what E2 told him/her. Then the child was interviewed as to why E2 provided the false testimony, “(E2's name) said the prize was in the (F), but you found it in the (C). Why did she say it's in the (F)'? If the child did not answer spontaneously, two choices were provided, "Do you think she tricked us, or do you think she just made a mistake"? The order of these two choices was counterbalanced.

\section{Coding and Reliability}

E1 coded children's searching patterns and explanations immediately after the experiment. A research assistant later coded the responses of all children from video recordings, and $100 \%$ agreement was established.

\section{Results}

Preliminary analyses were conducted to examine whether the arrangement of the containers and multiple experimenters in each condition influenced children's searching behavior. Neither effect was significant. In addition, analyses were conducted to examine whether demographic factors, such as children's gender religious background and location of residence contributed to their searching patterns. Results were not significant, and thus these variables were not included in the main analyses reported here (see Appendix). Table 1 describes children's demographic information by condition and age.

The first set of analyses explored children's trust in the false testimony when searching for the hidden toy. Chi-square tests were conducted throughout the analyses due to the categorical nature of the present study's data. These specific tests examined the effects of condition and age. Then children's credulity to the false testimony was compared to chance 
expectations. In addition, a logistic regression was conducted to explore whether age in months and level of exposure to different ethnicities predicted the likelihood of children being credulous. The second set of analyses examined children's explanations of the false testimony as compared to chance. All reported $p$ values were two tailed.

Table 1.

Group Descriptors by Condition and Age

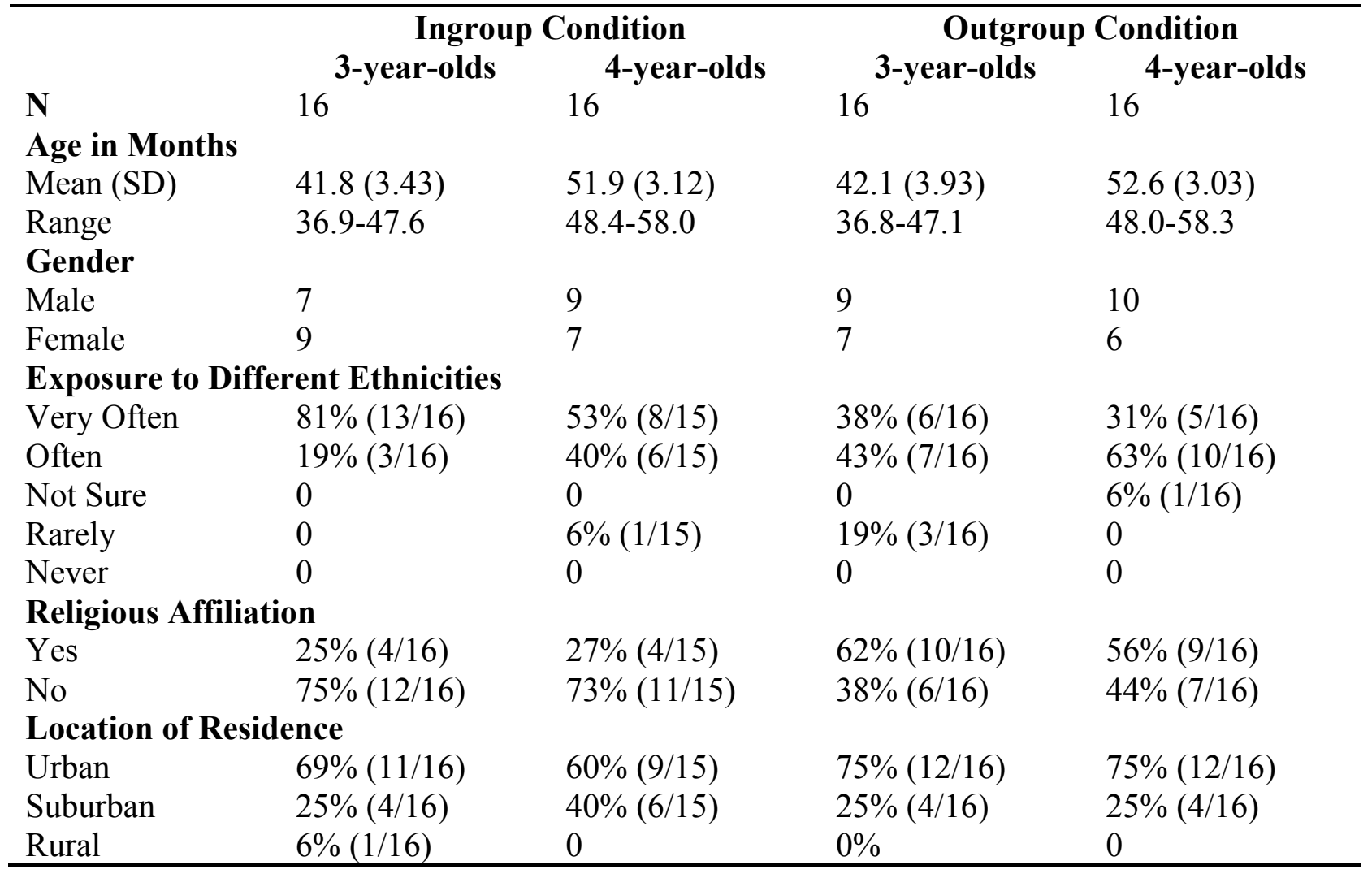

\section{Children's Trust in the False Testimony}

Separate Chi-Square tests of Independence were conducted to examine the main effects of condition (Ingroup vs. Outgroup) and age (3 vs. 4 years) on children's trust in the false testimony. The location where the child first searched for the hidden toy was the dependent 
variable. This was coded as " 1 " if the child searched in C first (i.e., being skeptical) or " 0 " if the child searched in F first (i.e., being credulous). No children chose the neutral container first.

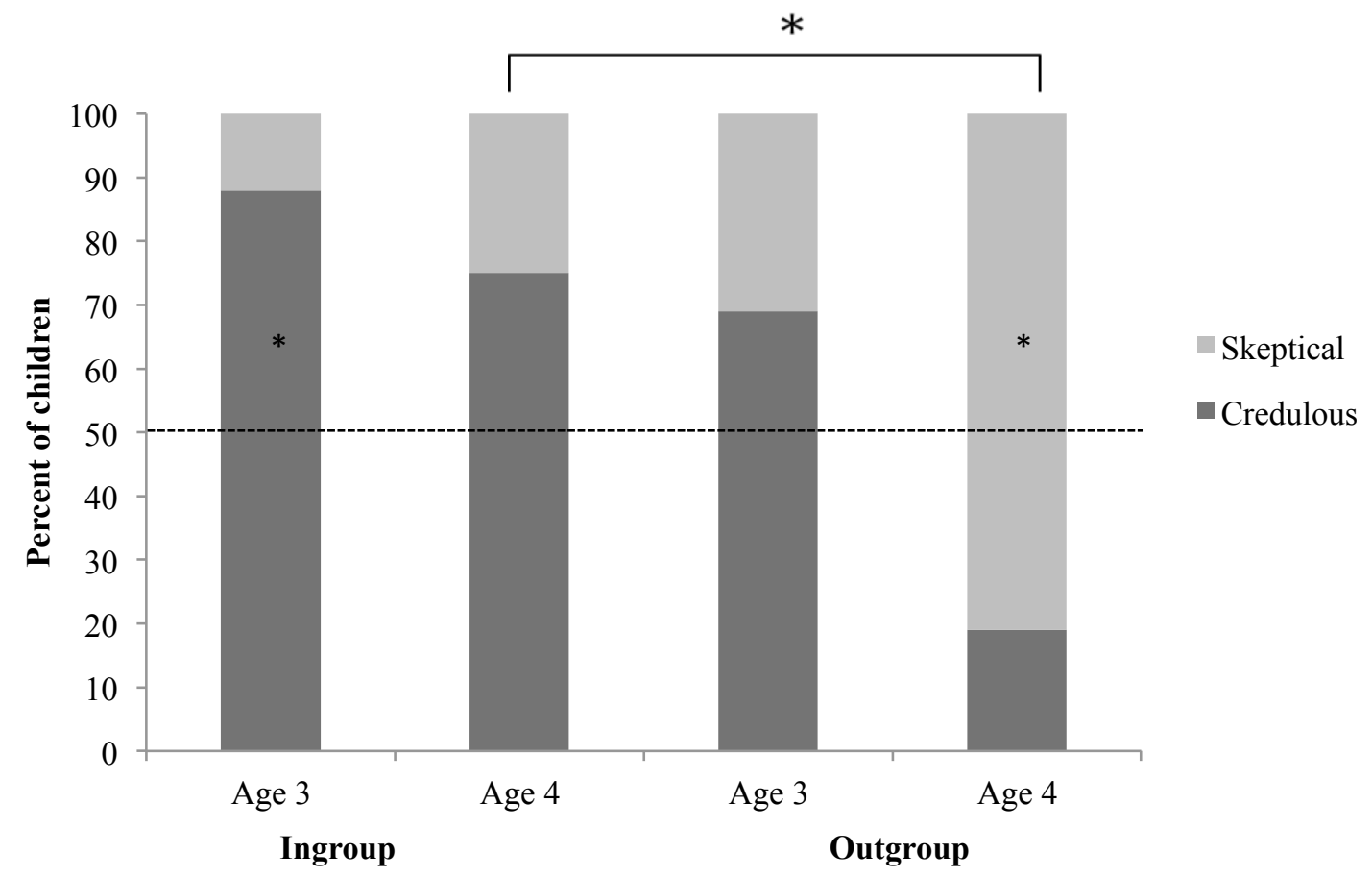

Figure 2. Percent of children who were credulous or skeptical in response to the false testimony (by condition and age)

The results indicated a significant effect of condition, $\chi^{2}(1)=9.6, p=.002$. Children were more likely to search for the toy based on their own observations and display skepticism of the false testimony when E2 was an outgroup than ingroup member. The effect of age was also significant, $\chi^{2}(1)=6.67, p=.01$. In general 4-year-old children were more likely to demonstrate skepticism of E2's false testimony than 3-year-olds.

Further analyses were conducted to explore the effect of condition by age group (i.e., whether the effect of condition was significant in both age groups). There was no significant effect of condition in 3-year-olds, $\chi^{2}(1)=1.65, p=.20$, ns, that is, 3-year-olds were equally credulous toward the false testimony of E2 across conditions. However, 4-year-olds were more 
likely to search for the toy based on their own observations and display skepticism of the false testimony when E2 was an outgroup than ingroup member, $\chi^{2}(1)=10.17, p=.001$.

Children's performance was then compared to chance expectations. As shown in Figure 2 , in the Ingroup condition, most 3-year-olds $(88 \%, 14 / 16)$ and 4 -year-olds $(75 \%, 12 / 16)$ were credulous and relied on E2's false testimony to retrieve the toy, despite their firsthand observations (as compared to chance $50 \%{ }^{1}$ ), $\chi^{2}(1)=9.00, p=.003$, and $\chi^{2}(1)=4.0, p=.05$, respectively. In the Outgroup condition, most 3 -year-olds were credulous $(69 \%, 11 / 16), \chi^{2}(1)=$ $2.25, p=.13$; in contrast, most 4-year-olds $(13 / 16,81 \%)$ were skeptical of E2's false testimony and relied on their firsthand observations to retrieve the toy, $\chi^{2}(1)=6.25, p=.01$.

A logistic regression was conducted to explore whether children's age in months and level of exposure to multiple ethnicities served as significant predictors of children's trust in the false testimony of outgroup speakers. See Table 2 for a description of the model.

Table 2.

Logistic Regression with Age in Months and Exposure to Different Ethnicities as Predictors (Outgroup)

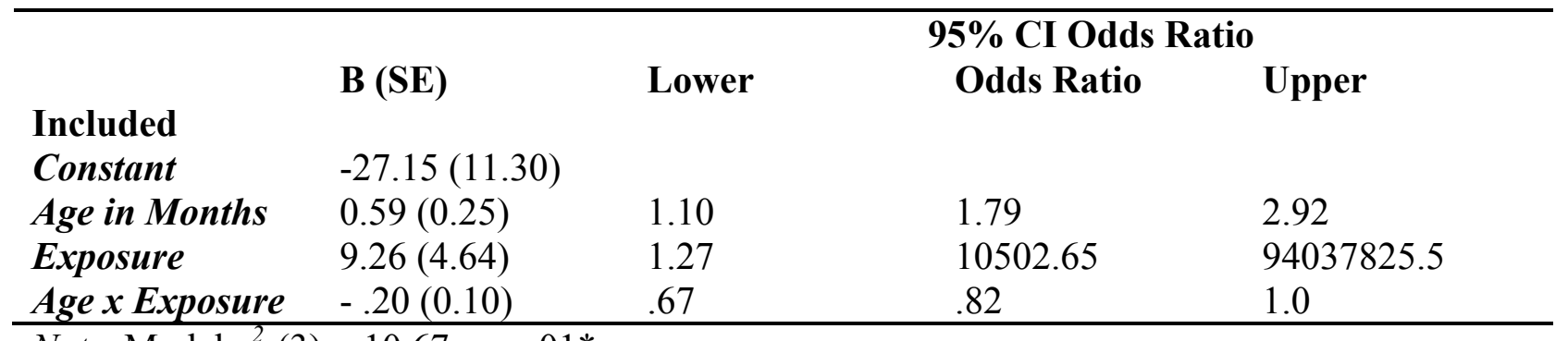
Note. Model $\chi^{2}(3)=10.67, p=.01^{*}$.

Overall the model correctly classified $56 \%$ of the children as skeptical or credulous when the two predictors were not included. Including both predictors and their interaction at step 1 significantly increased the model's predictive ability and enabled it to correctly classify $75 \%$ of

\footnotetext{
${ }^{1}$ Chance was set at $50 \%$ instead of $33.3 \%$ due to its more conservative nature. Children had the option of choosing among three containers (e.g., correct, false, and neutral). However, none of the children searched in the neutral container first, thus chance was set at $50 \%$ for more strict comparisons.
} 
the children, $p=.01$. The residual chi-square statistic indicated that age in months was a significant predictor to children's trust in the false testimony, $\chi^{2}(1)=4.44, p=.04$. More specifically, the likelihood of children being skeptical of the false testimony increased with age. However, the level of exposure to different ethnicities and the interaction between this exposure and age did not appear to contribute significantly as predictors, $\chi^{2}(1)=.27, p=.60 \mathrm{~ns}$, and $\chi^{2}(1)$ $=.92, p=.34 \mathrm{~ns}$, respectively.

\section{Children's Explanations of the False Testimony}

Table 3 describes children's responses to the two memory-check questions. The majority of them correctly remembered where E2 put the toy and where E2 claimed the toy was.

Table 3 .

Children's Responses to the Memory-Check Questions by Age and Condition

\begin{tabular}{lcccc}
\hline Question & \multicolumn{2}{c}{$\begin{array}{c}\text { Ingroup } \\
\text { Percent Correct }\end{array}$} & \multicolumn{2}{c}{$\begin{array}{c}\text { Outgroup } \\
\text { Percent Correct }\end{array}$} \\
& 3-year-olds & 4-year-olds & 3-year-olds & 4-year-olds \\
$\begin{array}{l}\text { Where did E2 } \\
\text { put the toy? }\end{array}$ & $88 \%(14 / 16)$ & $87 \%(14 / 16)$ & $81 \%(13 / 16)$ & $93 \%(15 / 16)$ \\
$\begin{array}{l}\text { Where did E2 } \\
\text { say the toy was? }\end{array}$ & $75 \%(12 / 14)$ & $80 \%(13 / 16)$ & $62 \%(10 / 16)$ & $87 \%(14 / 16)$ \\
\hline
\end{tabular}

Figure 3 describes children's explanations of why E2 provided the false testimony. Across the two conditions, one 3-year-old child did not respond, and one responded spontaneously (i.e., no forced-choice options were provided) by stating that E2 was trying to trick them. All 4-year-olds provided explanations, and 12 of them responded spontaneously by stating that E2 was trying to trick them. Separate Chi-Square tests were conducted to examine the main effects of condition (Ingroup vs. Outgroup), children's response (Credulous vs. Skeptical), and age ( 3 vs. 4 years) on children's explanations of the false testimony. The results 
indicated no significant effect of condition, $\chi^{2}(2)=1.41, p=.49$, ns. E2's false testimony was explained similarly regardless of speaker social category: Children explained the event similarly (e.g., trick versus mistake) in both the ingroup and outgroup conditions. In addition, there was no significant effect of response, $\chi^{2}(2)=.65, p=.72$, ns. Whether or not children were credulous (or skeptical) did not appear to influence their explanation of the false testimony. However, the effect of age was significant, $\chi^{2}(2)=8.81, p=.01$. Four-year-old children were more likely to state that E2 was tricking them than 3-year-olds were.

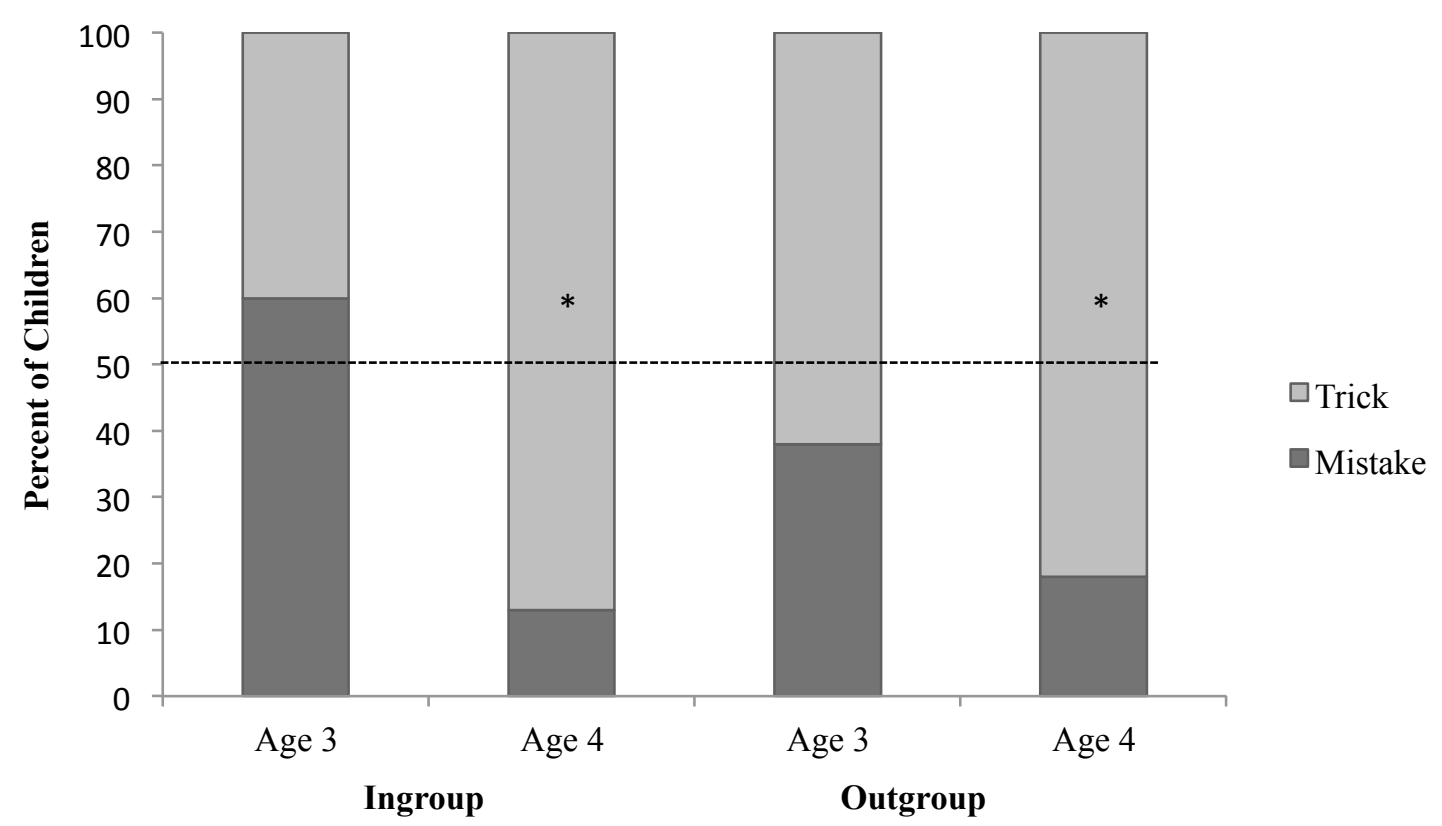

Figure 3. Percent of children that explained E2's false testimony as a trick or mistake

Children's performance was then compared to chance expectations. As shown in Figure 3, in the Ingroup condition, 3-year-olds explained E2's actions as a Mistake or Trick indiscriminately, $\chi^{2}(1)=.60, p=.44$, ns. In contrast, most 4-year-olds in the Ingroup condition explained E2's actions as a Trick, and not a mistake $\chi^{2}(1)=9.00, p=.003$. Similarly, in the Outgroup condition, 3-year-olds showed no significant differences in explaining the event as a 
Mistake or Trick, $\chi^{2}(1)=1.00,, p=.31$, ns. Four-year-olds, however were more likely to explain E2's actions as Trick versus a Mistake, $\chi^{2}(1)=6.25, p=.01$.

\section{Discussion}

The present data indicate that 4-year-old children were credulous toward the false testimony of an ingroup speaker that shared their ethnicity and accent, despite their firsthand observations of the event. When the false testimony was provided by an outgroup speaker from a different ethnic group and with a foreign accent, 4-year-olds were skeptical and relied on their own observations of the event to solve the problem. In contrast, 3-year-old children were credulous toward the false testimony of both speakers regardless of their ethnicities. The following section will discuss (1) the effect of speaker ethnicity on young children's trust in the testimony of others, (2) the developmental differences observed between 3- and 4-year-old children's credulity, and (3) children's explanations of the false testimony.

\section{The Effect of Speaker Ethnicity}

It is important to note that in the present study, the role of speaker ethnicity in children's trust was explored by examining the joint effect of race and accent, as previous findings indicate that younger children do not display biases for members of their own race (Aboud, 2003; Furby, 1971), but do demonstrate preferences for those that speak with their native accent (Kinzler, et al., 2007; Kinzler et al., 2010: Kinzler \& Spelke, 2011; Kinzler \& DeJesus, 2012; Moon et al., 1993; Shutts et al., 2010). It was necessary however to examine the joint effect of both race and accent initially because the present study employed a different paradigm, and thus, results may differ from previous studies when children have access to direct observations.

Four-year-olds were credulous toward the false testimony of a speaker from their ethnic ingroup but skeptical of an outgroup speaker. How can we explain this effect? The first 
possibility is that young children have preferences for ingroup members from early on, which may later develop into an attachment or closeness to ingroups that fosters trust in the testimony of ingroup speakers. Second, it is possible that children have a greater tendency to conform to what they are told by ingroup than outgroup members. Lastly, children may attribute low confidence or ignorance to outgroup speakers and are more confident in their own observations.

Preferences for ingroups. Children's credulity toward members of their ethnic ingroup may arise from their early favoritism toward ingroup members, such as preferences for faces of their own race (e.g., Bar-Haim, et al., 2006; Kelly et al., 2005; Kelly et al., 2007) and for social others that speak their native language or share their native accent (Kinzler, et al., 2007; Kinzler et al., 2010: Kinzler \& Spelke, 2011; Moon et al., 1993; Shutts et al., 2010). These early preferences may later develop into an ingroup attachment or closeness that makes it more adaptive to learn about the world from ingroup members (Tomasello, 2008). Children may assume that those who look and sound like them may also share other similar characteristics, such as religion or food choices, and naturally learning from those individuals makes more sense evolutionary. Moreover, earlier ingroup attachment or favoritism develops more strongly than outgroup skepticism or prejudice (Allport, 1954; Cameron, Alvarez, Ruble, \& Fuligni, 2001).

In line with this explanation, the present study revealed that the 4-year-olds displayed persisting trust in ingroup rather than outgroup speakers, choosing to rely on a false testimony despite their direct observations. Because the ingroup speaker resembled children in both appearance and accent, it is possible that a form of credibility was implicitly attached to the speaker that otherwise was not granted to an outgroup speaker (Brewer, 1999). Kinzler and colleagues (2010) found support for this explanation even when native-accented individuals spoke in nonsense speech or were providing non-linguistic information. The present study 
extends previous findings, by showing that the favoritism toward ingroups is so powerful that it may lead to "blind trust": A false claim from a member of children's ingroup may suspend their own beliefs even when they have direct access to the truth.

Conformity to the testimony of ingroups. It is possible that children in the present study were hesitant to act as dissenters to statements (false or otherwise) provided by ingroup members. Children are sensitive to consensus information, and prefer to seek information from members belonging to a majority group (Corriveau et al., 2009). More importantly, when the majority group (i.e., the nondissenters) consists of individuals all from their ethnic ingroup, children continue to prefer one of the nondissenters over the dissenter as sources of information. This effect is not evident when the majority group consists of both ingroup and outgroup informants (Chen et al., 2012). In light of these findings, children in the current study might have a greater tendency to conform to the opinions of ingroup than outgroup members, which may explain why children were credulous toward what they were told by the ingroup speaker even when the testimony was obviously false and contradicted their firsthand observations.

Negative perceptions about outgroups. A third possibility is that children identified non-native speakers as less credible, and detected that a mistake was made when the false testimony was relayed (e.g., a language error). There is evidence that a speaker with a heavy accent might be perceived as less confident or less credible (Flege, 1988; Lev-Ari \& Keysar, 2010). For example, trivial statements (e.g., pigs can't cry) are judged as less true when spoken by non-native speakers with an accent than native speakers. Moreover, these statements are not rated as difficult to understand, but rather viewed as false testimonies (Lev-Ari \& Keysar, 2010). This suggests that even when statements are comprehended successfully, non-native speakers are perceived as less credible when they are providing information. As previously mentioned, 
children are more willing to trust speakers they view as knowledgeable (Sabbagh \& Baldwin, 2001; Harris \& Koenig, 2005), and demonstrate a general orientation to perceive ingroup, but not outgroup speakers under a "halo" (Brosseau-Liard \& Birch, 2011; Kinzler et al., 2007; Koenig \& Jaswal, 2011). Furthermore, children might assume ingroup members are incapable of making such an obvious error in testimony, and may not hold this standard for outgroup members.

To summarize, the observed effect of speaker ethnicity on 4-year-olds might be explained by preferences for ingroups, conformity to ingroups, or negative perceptions about outgroups. It is important to note that these three accounts are likely not mutually exclusive. They may work in combinations or serve to preclude each other. Developing preferences for ingroup members may create negative perceptions about outgroup members (Files, et al., 2010). For example, it may be easier to forgive ingroup members shortcomings and narrow in on transgressions made by outgroup members. The media may also assist in this process. In addition, it is possible that children's conformity to the false testimony provided by ingroup members is dependent on their preferences for those speakers, and it is unlikely that they would conform towards those they have negative feelings for.

\section{Developmental Differences}

Four-year-olds, but not 3-year-olds, were skeptical of the false testimony provided by an outgroup member. This age difference might be explained by a greater ingroup favoritism in 4year-olds due to greater exposure to biases against outgroup members or more opportunities to develop preferences for ingroup members. Secondly, when a false claim is provided by an outgroup member, 4-year-olds may have more confidence in their own observations and are thus more capable of acting skeptically. Finally, developmental differences in overall cognitive abilities may explain the observed age effect. 
Exposure to outgroup stereotypes. Most 4-year-olds in Canada, but not 3-year-olds are enrolled in Junior Kindergarten (JK) and get exposed to not only different ethnicities but also the stereotypes and biases held by others (Aboud, 1988; Baron \& Banaji, 2006). These biases may develop implicitly within 4-year-olds, due to immersion with others who are more explicit about their preferences (Baron \& Banaji, 2006). According to past research, ingroup biases increase significantly from age 3 to 5 years in accordance with developing social cognitive abilities (Clark, Hocevar, \& Dembo, 1980; Katz \& Kofkin, 1997). Young children have difficulties separating their own beliefs about ethnic group members from popular stereotypes (Augoustinos \& Rosewarne, 2001), and it is likely that 4-year-olds in the present study were influenced by several sources in JK. The experiences and attitudes of parents, teachers, and peers may shape preschoolers' developing schemas of different ethnic groups. More specifically, ingroup biases may become more prevalent in 4-year-olds because they have more opportunities in JK to develop negative perceptions of outgroup members through hearing the opinions and stereotypes held by their peers, and by media presented in academic activities that 3 -year-olds may not have access to (Roberts, 2000; Wright et al., 2001; Vandewater et al., 2007).

Confidence. It is also conceivable that 4-year-old children simply have more experience being "correct" in their judgments, which increases their confidence and ability to act skeptically when it is warranted. Although most young children view visual perception as a reliable way to observe an event (O’Neil et al., 1992), younger children may be less confident in their own judgments. As Ma \& Ganea (2010) explained, children may choose to rely on an adult's false testimony because of the novelty of the situation, despite typically being confident in their everyday visual observations. Although most 3-year-old children were credulous to the false testimony, this interpretation does not explain why almost as many 4-year-old children relied on 
the false testimony provided by the ingroup speaker. It is possible that both groups were more trusting of ingroup members, and perceived outgroup members as less credible, but due to different confidence levels, only 4-year-olds were able to act skeptically when they sensed the speaker was less credible.

Cognitive abilities. Children as young as 3 years understand that in some circumstances all people do not perceive the same object in the same way (Flavell, 1978; Flavell, Everrett, Croft, \& Flavell, 1981), despite typically being egocentric about the world (Piaget, 1926). However, 3-year-olds may have difficulties appreciating more complex mental states (see Wellman, et al., 2002 for a meta-analysis), such as understanding that some beliefs can be held inaccurately and do not always correspond to reality (e.g., a false belief). In typically developing populations, a false-belief understanding develops with age with most children achieving this ability reliably between 4 to 5 years (Wellman et al., 2002).

Recent research shows that the ability to pass false-belief tasks is associated with the ability to display selective trust in others (Diyanni et al., 2012; Lucas et al., 2012). Children who pass false-belief tasks are consistently able to assess speaker reliability when deciding whether an informant is trustworthy in a subsequent situation. Thus, given 3-year-old children's general difficulty in false-belief tasks, it is possible that in the present study they did not have the relevant cognitive abilities to adequately assess speaker credibility against their firsthand observations.

Previous research demonstrates that the development of general cognitive processes such as executive function, support the development of overall social cognitive abilities (Carlson \& Moses, 2001). Specifically, inhibitory control, the ability to pursue a goal while resisting or "inhibiting" responses to other stimuli, increases with age and relates to the development of 
mental-state understanding (Carlson \& Moses, 2002). Preschool children that pass inhibitory control measures typically pass false-belief tasks as they are able to inhibit their own perspectives of an event to appreciate that others may hold alternate perspectives (Carlson \& Moses, 2002). Not surprisingly, a new line of research has demonstrated that inhibitory control may share a relationship with the development of selective trust (Jaswal et al., 2013). Using a research paradigm similar to the one used in the present study, researchers have found that children with developed inhibitory control processes would inhibit believing a "false testimony", and rely more easily on what was actually observed (Jaswal et al., 2013).

It is conceivable that 4-year-olds in the present study have more advanced cognitive processes (e.g., mental-state understanding and executive control) than 3-year-old children (Carlson \& Moses, 2001; Gopnik \& Astington, 1988; Wellman et al., 2002), although no direct measures of inhibitory control or false-belief understanding were administered.

This interpretation explains why more 4-year-olds compared to 3-year-olds displayed a skeptical response to the false testimony provided by the outgroup speaker, but it does not explain why significant differences were observed between the two groups of 4-year-olds (i.e., the condition effect). The results were likely influenced by the combination of 4-year-olds' more developed cognitive processes and the speaker's social category. Because ingroup preferences were held, when a trusted ingroup member relayed the false testimony, it might not be necessary for 4-year-olds to act skeptically and inhibit the provided information. In contrast, it is possible that when an outgroup member associated with negative perceptions relayed the false testimony, due to inhibitory control, 4-year-olds were capable of rejecting the false testimony and relied on their own observations. Because 3-year-old children have overall difficulties inhibiting unwanted information, speaker social category had no effect on their trust in the false testimony. 
It is possible that 3-year-old children can learn to inhibit unwanted information when they are primed in advance with a speaker who was previously unreliable, or inaccurate (Ma \& Ganea, 2010; Koenig \& Harris, 2005), as a recent study reveals that speaker past accuracy is more influential than speaker accent or group membership when children are endorsing novel object labels or functions (Corriveau, et al., 2013).

Finally, individual differences can explain a portion of children's responses, though a clear pattern does exist between the two groups. Children in the study were raised in different environments, with different parents, customs, and lifestyles. It can thus be assumed, that alternate interpretations can explain some children's willingness to accept the false testimony over others. For example, previous research suggests that differences in children's attachment style (i.e., secure, insecure-avoidant, and insecure-resistant) mediated children's trust in their mother's versus a stranger's claims (Corriveau et al., 2009). For example, children who had developed a secure attachment chose to endorse the claims provided by both a stranger and a familiar caregiver depending on the situational relevance. In contrast insecure-resistant children typically only accepted information from a familiar caregiver, and insecure-avoidant children were more likely to accept information from a stranger (Corriveau et al., 2009). These results do not explain the current study's findings, but they can shed light on the response pattern of a select few children and should be considered along with overall differences in cognitive abilities.

\section{Explanations of the False Testimony}

More 3-year-olds than 4-year-olds stated that the speaker made a mistake versus playing a trick when relaying the false testimony. It's possible that Four-year-old children initially viewed the act as a mistake, but after further reflection, they were able to inhibit previous assessments of the event and critically uncover what actually occurred (Carlson \& Moses, 2001; 
Wellman et al., 2002), though there was no measure that directly assessed this interpretation. It is more obvious upon reflection for children to report they were being tricked, as the experiment mimics a game of hide-and-seek, a form of play most children have encountered frequently prior to the experiment. In contrast, 3-year-olds may not reflect on the situation as deeply, and stick to their original assumption that the experimenter made a mistake (regardless of where they actually looked for the toy). Consistent with the present study, past findings reveal that younger children are less likely to report that an experimenter lied (even when that was clearly the case) (Berthoud-Papandropoulou \& Kilcher, 2003; Ma \& Ganea, 2010).

\section{Future Directions for Research}

In the present study group membership was marked by both race and accent. There are still open questions as to which marker influenced 4-year-old children's skeptical response, or whether it was a combination of the two markers. Future work is needed to elucidate these questions. A follow-up study will need to tease apart (1) the effect of speaker race, controlling for speaker accent, and (2) the effect of speaker accent, controlling for speaker race.

In addition, future research should seek to examine how children from other ethnic backgrounds (i.e., not just Caucasian, native English speaking children) differ in their credulity toward the false testimony of others. For example, English speaking minority children with a foreign accent who receive false testimony from a minority speaker with a similar accent (ingroup), or from a Caucasian, native English speaker (outgroup). Previous research has shown that minority children (e.g., Black children) do not have ingroup favoritism or outgroup biases against majority children (e.g., White children) (Shutts, Kinzler, Katz, Tredoux, \& Spelke, 2011). Thus, it is possible that minority children will not show an ingroup bias in the present study, but rather conform to majority outgroup members. 
Another follow-up study could explore how native English-speaking minority children respond to false testimony from a minority speaker with a non-native accent, or from a native English speaker. It is possible that children may act more skeptically towards the speaker with the non-native accent, regardless of group membership (Kinzler et al., 2007). This manipulation would help to tease apart the effects of accent and race on children's credulity towards false testimony.

Lastly, it would be highly interesting to explore how children of minority status that have been adopted by Caucasian, native English speaking parents respond to false testimony from a minority speaker versus a Caucasian, native English speaker. It is likely that children's responses will depend on whether they identify the speaker as ingroup or outgroup. Studying questions like this could shed light on how children's identity formation influences their trust in speakers from different ethnic backgrounds.

\section{Implications}

Predominantly, this research adds novel contributions to the literature on social-cognitive development, as there have been limited reports on children's trust in individuals from different social categories. Although children are reported to display preferences for and endorse testimony provided by speakers of their own social group, no studies have examined whether children will rely on an outgroup member's testimony when it contradicts their own observations. In addition, findings of this research can be applied to relevant social situations. For example, future research should seek to understand the direction of the relationship in 4year-olds' selective trust and the development of prejudice and cliques in childhood. Lastly, children are also reported to be susceptible to misinformation from others, in the justice system (e.g., eye-witness testimony) and in everyday life (Ceci \& Bruck, 1993). When children display 
trust in others over their own ideas or observations, it is possible for them to be coerced by several individuals (e.g., law enforcement members) in criminal matters. Studying why and whom children are more apt to "believe" in a situation where misinformation is involved thus has important practical implications. 


\section{References}

Aboud, F. E. (1988). Children and prejudice. New York: Blackwell.

Aboud, F. E. (2003). The formation of in-group favoritism and out-group prejudice in young children: Are they distinct attitudes. Developmental Psychology, 39, 48-60.

Ackerman, B. P. (1983). Speaker bias in children's evaluation of the external consistency of statements. Journal of Experimental Child Psychology, 35, 111-127.

Akhtar, N., Menjivar, J., Hoicka, E., \& Sabbagh, M. A. (2012). Learning foreign labels from a foreign speaker: The role of (limited) exposure to a second language. Journal of Child Language, 1-15.

Allport, G. W. (1954). The nature of prejudice. Cambridge, MA: Addison- Wesley.

Astington, J. W., \& Jenkins, J. M. (1999). A longitudinal study of the relation between language and theory-of-mind development. Developmental Psychology, 35, 1311-1320.

Augoustinos, M., \& Rosewarne, D. L. (2001). Stereotype knowledge and prejudice in children. British Journal of Developmental Psychology, 19, 143-156.

Bar-Haim, Y., Ziv, T., Lamy, D., \& Hodes, R. M. (2006). Nature and nurture in own-race face processing. Psychological Science, 17, 159-163.

Baron-Cohen, S., Leslie, A. M., \& Frith, U. (1985) Does the autistic child have "theory of mind"? Cognition, 21, 37-40.

Baron, A. S., \& Banaji, M. R. (2006). The development of implicit attitudes. Psychological Science, 17, 53-58.

Berthoud-Papandropoulou, I., \& Kilcher, H. (2003). Is a false belief statement a lie or a truthful statement? Judgments and explanation of children aged 3 to 8. Developmental Science, 6, 173-177. 
Best, C. T., Tyler, M. D., Gooding, T. N., Orlando, C. B., \& Quann, C. A. (2009). Development of phonological constancy: Toddlers' perception of native- and Jamaican-accented words. Journal of the Association of Psychological science, 20, 539-542.

Bigler, R. S., \& Liben, L. S. (1993). A cognitive-developmental approach to racial stereotyping and reconstructive memory in Euro-American children. Child Development, 64, 15071519.

Billig, M., \& Tajfel, H. (1973). Social categorization and similarity in intergroup behavior. European Journal of Social Psychology, 3, 27-52.

Bonilla-Silva, E. (1997). Rethinking racism: Toward a structural interpretation. American Sociological Review, 62, 465-480.

Boyatzis, C. J., \& Varghese, R. (1993). Children's emotional associations with colors. Journal of Genetic Psychology, 155, 77-85.

Brewer, M. B. (1999). The psychology of prejudice: In-group love or out-group hate? Journal of Social Issues, 55, 429-444

Brosseau-Liard, P.E., \& Birch, S. A. J. (2011). Epistemic states and traits: Preschoolers appreciate the differential informativeness of situation-specific and person-specific cues to knowledge. Child Development, 82, 1788-1796

Cameron, J. A., Alvarez, J. M., Ruble, D. N., \& Fuligni, A. J. (2001). Children's lay theories about in-groups and out-groups: Reconceptualizing research on prejudice. Personality and Social Psychology Re-view, 5, 118-128.

Campos, J. J. (1980). Human emotions: their new importance and their role in social referencing. Research \& Clinical Center for Child Development; Annual report.

Carlson, S. M., \& Moses, L. J. (2001). Individual differences in inhibitory control and children's 
theory of mind. Child Development, 72, 1032- 1053.

Ceci, S. J., \& Bruck, M. (1993). Suggestibility of the child witness: A historical review and synthesis. Psychological Bulletin, 113, 403-439.

Chen, E. E., Corriveau, K. H., \& Harris, P. L. (2012). Children trust a consensus composed of outgroup members- But do not retain that trust. Child Development, 0, 1- 14.

Chow, V., Poulin-Dubois, D., \& Lewis, J. (2008). To see or not to see: Infants prefer to follow the gaze of a reliable looker. Developmental Science, 11, 761-770.

Clark, A., Hocevar, D., \& Dembo, M. H. (1980). The role of cognitive development in children's explanations and preference for skin colour. Developmental Psychology, 16, 332-339.

Clement, F., Koenig, M., \& Harris, P. (2004). The ontogenesis of trust. Mind \& Language, 19, $36-379$.

Corriveau, K., \& Harris, P. L. (2009). Choosing your informant: Weighing familiarity and recent accuracy. Developmental Science, 12, 426-437.

Corriveau, K. H., Fusaro, M., \& Harris, P. L. (2009). Going with the flow: Preschoolers prefer non-dissenters as informants. Psychological Science, 20, 372-377.

Corriveau et al., (2009). Young chidlren's trust in their mother's claims: Longitudinal links with attachment security in infancy. Child Development, 80, 750-761.

Corriveau, K. H., Harris, P., \& Kinzler, K. D. (2013). Accuracy trumps accent in children's endorsement of object labels. Developmental Psychology, 49, 470-479.

Diyanni, C., Nini, D., Rheel, W., \& Livelli, A. (2012). “I won’t trust you if I think you're trying to deceive me": Relations between selective trust, theory of mind, and imitation in early childhood. Journal of Cognition and Development, 13, 354-371. 
Einav, S., Robinson, E. J. (2010). When being right is not enough: Four-year-olds distinguish knowledgeable informants from merely accurate informants. Psychological Science, 10, $1250-1253$.

Esbensen, B. M., Taylor, M., \& Stoess, C., (1997). Children's behavioural understanding of knowledge acquisition. Cognition Development, 12, 53-84.

Federal Interagency Forum on Child and Family Statistics (2010). America's children in brief: Key national indicators of well-being, 2010. Washington, DC: US Government Printing Office.

Feinman, S., \& Lewis, M. (1983). Social referencing at 10 months: a second order effect on infant

Files, J. S., Casey, C. M., \& Oleson, K. C. (2010). Intergroup bias in children: Development and persistence. European Journal of Social Psychology, 40, 671-678.

Flege, J. E. (1988). Factors affecting degree of perceived foreign accent in English sentences. Journal of Acoustical Society in America, 84, 70-79.

Flavell, J. H. (2004). Theory-of-mind development: Retrospect and prospect. Merrill-Palmer Quarterly, 50, 274-290.

Flavell, J. H., Shipstead, S.G., \& Croft, K. (1978). Young children's knowledge about visual perception: hiding objects from others. Child Development, 49, 1208-1211.

Flavell, J. H., Everett, B. A., Croft,K., \& Flavell, E. R. (1981). Young children's knowledge about visual perception: Further evidence for the Level 1-Level 2 distinction. Developmental Psychology, 17, 99-103.

Furby, L., \& Kircher, M. (1973). Racial preferences in young children. Child Development, 42, 2076-2078. 
Gelman, S. A. (2009). Learning from others: Children's construction of concepts. Annual Review of Psychology, 60, 115-140.

Gopnik, A. \& Astington, J. W. (1988). Children's understanding of representational change and it's relation to the understanding of false-belief and appearance- reality. Child Development, 59, 26-37.

Grossman, J. B., Klin, A., Carter, A.S. \& Volkmar, V.F. (2000) Verbal bias in recognition of facial emotions in children with asperger syndrome. Journal of Child Psychology and Psychiatry, 41, 369-79.

Harris, P. (2007). Trust. Developmental Science, 10, 135-138.

Harris, P., \& Koenig, M. A. (2006). Trust in testimony: How children learn about science and religion. Child Development, 77, 505-524.

Harris, P., Pasquini, E., Duke, S., Assher, J., \& Pons, F. (2006). Germs and angels: The role of testimony in young children's ontology. Developmental Science, 9, 76-91.

Hirschfield, L., \& Gelman, S. (1997). What young children think about the relationship between language variation and social difference. Cognitive Development, 12, 213-238.

Jared, D., Cormier, P., Levy, B. A., \& Woolley, L.W. (2010). Early predictors of bilteracy development in children in French immersion: A 4-year longitudinal study. Journal of Educational Psychology, 103, 119-139.

Jaswal, K., Perez-Edgar, K., Kondrad, R., Palmquist, C., Cole, C., \& Cole, C. (2013, April). Individual differences in skepticism to misleading testimony. Symposium presentation at the Biennial Meeting of the Society for Research in Child Development, Seattle, WA. Kalish, C. W. (2002). Children's predictions of consistency in people's actions. Cognition, 87, 179-203. 
Katz, P. A., \& Kofkin, J. A. (1997). Race, gender and young children. In S. S. Luthar, J. A. Burack, D. Cicchetti, \& J. Weisz (Eds.), Developmental psychopathology: Perspectives on adjustment, risk, and disorder (pp. 51-74). New York: Cambridge University Press.

Kelly, D. J., Quinn, P. C., Slater, A. M., Lee, K., Gibson, A., Smith, M., Ge, L., \& Pascalis, O. (2005). Three-month-olds, but not newborns, prefer own-race faces. Developmental Science, 8, 31-36.

Kelly, D. J., Liu, S., Liezhong, G., Quinn, P. C., Slater, A. M et al. (2007). Cross-race preferences for same-race faces extend beyond the African versus Caucasian contrast in 3month-old infants. Infancy, 11, 87-95.

Kinzler, K. D., Dupoux, E., \& Spelke, E. (2007). The native language of social cognition. PNAS, 104,12577-12580.

Kinzler, K. D., Corriveau, K. H. \& Harris, P. L. (2010). Children's selective trust in nativeaccented speakers. Developmental Science, 10,1-6.

Kinzler, K. D., Shutts, K., DeJesus, J., \& Spelke, E. S. (2009). Accent trumps race in guiding children's social preferences. Social Cognition, 27, 623-634.

Kinzler, K. D., \& Spelke, E. S. (2011). Do infants show social preferences for people differing in race? Cognition, 119, 1-9.

Kinzler, K. D. \& DeJesus, J. M. (2013). Children's sociolinguistic evaluations of nice foreigners and mean Americans. Developmental Psychology, 49, 655-664

Koenig, M., Clement, F., \& Harris, P. L. (2004). Trust in testimony: Children's use of trust and false statements. Psychological Science, 10, 694-698.

Koenig, M. A., \& Echols, C. H. (2003). Infants' understanding of false labeling events: The referential roles of words and the speakers who use them. Cognition, 87, 179-203. 
Koenig, M. A., \& Harris, P. L. (2005). Preschoolers mistrust ignorant and inaccurate speakers. Child Development, 76, 1261-1277.

Koenig, M. A., \& Woodward, A. L. (2012). Toddlers learn words in a foreign language: The role of native vocabulary knowledge. Journal of Child Language.

Koenig, M. A., \& Jaswal, V. K. (2011). Characterizing children's expec- tations about expertise and incompetence: Halo or pitchfork effects? Child Development, 82, 1634-1647.

Labov, W. (2006). The social stratification of English in New York City (2nd edn.). New York: Cambridge University Press.

Lev-Ari, S., \& Keysar, B. (2010). Why don't we believe non-native speakers? The influence of accent on credibility. Journal of Experimental Social Psychology, 46, 1093-196.

Locksley, A., Ortiz, V., \& Hepburn, C. (1980). Social categorization and discriminatory behavior: Extinguishing the minimal intergroup discrimination effect. Journal of Personality and Social Psychology, 39, 773-783.

Lucas, A. J., Charlie Lewis, F., Pala, C., Wong, K., \& Berridge, D. (2013). Social-Cognitive Processes in preschoolers' selective trust: three cultures compared. Developmental Psychology, 49, 579-590.

Ma, L., \& Woolley, J. D. (2013). Young children's sensitivity to speaker gender when learning from others. Journal of Cognition and Development.

Ma, L., \& Ganea, P. A. (2010). Dealing with conflicting information: Young children's reliance on what they see versus what they are told. Developmental Science, 13, 151-160.

Maccoby, E. E. (1988). Gender as a social category. Developmental Psychology, 24, 755-765.

Moon, C., Cooper, R. P., \& Fifer, W. P. (1993). Two-day-olds prefer their native language. Infant Behaviour and Development, 16, 495-500. 
Mumme, D. L., Fernald, A., \& Herrera, C. (1996). Infants' responses to facial and vocal emotional signals in a social referencing paradigm. Child Development, 67, 3219-3237.

O’Neill, D. K., Astington, J. W., \& Flavell, J. H. (1992). Young children's understanding of the role that sensory experiences play in knowledge acquisition. Child Development, 63, 474490.

Pasquini, E. S., Corriveau, K., Koenig, M. A., \& Harris, P. L. (2006). Preschoolers monitor the relative accuracy of informants. Developmental Psychology, 43, 1216-1226.

Piaget, J. (1962). Play, dreams and imitation in childhood. London: Routlege \& Kegan Paul. Picariello, M., Greenberg, D., \& Pillemer, D. (1990). Children's sex-related stereotyping of colors. Child Development, 61, 1453-1460.

Pratt, C., \& Bryant, P. E. (1990). Young children understand that looking leads to knowing (so long as they are looking into a single barrel). Child Development, 61, 973-982.

Quinn, P. S., Yahr, J., Kuhn, A., Slater, A. M., \& Pascalis, O. (2002). Representation of the gender of human faces by infants: A preference for female. Perception, 31,1109-1121.

Roberts, D. F. (2000). Media and youth: Access, exposure, and privatization. Journal of Adolescent Health, 27, 8-14.

Sabbagh, M. A., \& Baldwin, D. A. (2001). Learning words from knowledgeable versus ignorant speakers: Links between preschooler's theory of mind and semantic development. Child Development, 72, 1054-1070.

Schmale, R., Hollich, G., \& Seidl, A. (2011). Contending with foreign accent in early word learning. Journal of Child Language, 38,1096-1108.

Shutts, K., Banaji, M. R., \& Spelke, E. S. (2010). Social categories guide young children's preferences for novel objects. Developmental Science, 13, 599-610. 
Shutts, K., Kinzler, K. D., Katz, R. C., Tredoux, C., \& Spelke, E. S. (2011). Race preferences in children: Insights from South Africa. Developmental Science, 14, 1283-1291.

Signorella, M. L., Bigler, R. S., \& Liben, L. S. (1993). Developmental differences in children's gender schemata about others: A meta-analytic review. Developmental Review, 13, 147183.

Tomasello, M., \& Barton, M. (1994). Learning words in non-ostensive contexts. Developmental Psychology, 30, 639-650.

Tomasello, M. (2008). The cultural origins of human cognition. Cambridge, MA: Harvard University Press.

Tenenbaum, H. R., Hill, D. B., \& Joseph, N. (2010). It's a boy because he's painting a picture: Age differences in children's conventional and unconventional gender schemas. British Journal of Psychology, 101, 137-154.

Vandewater, V. J., Rideout, E. A., Xuan Huang, W., Lee, J. H., \& Shim, M. (2007). Digital childhood: Electronic media and technology use among infants, toddlers, and preschoolers. Pediatrics, 119, 1006- 1015.

Wellman, H. M. (1990). Children's theories of mind. Cambridge, MA: Bradford/MIT Press.

Wellman, H. M., Cross, D., \& Watson, J. (2001). Meta-analysis of theory-of-mind development: The truth about false belief. Child Development, 72, 655-684.

Wimmer, H., \& Perner, J. (1983). Beliefs about beliefs: Representation and constraining function of wrong beliefs in young children's understanding of deception. Cognition, 13, 103-128.

Wellman, H. M., Cross, D., \& Watson, J. (2001). Meta-analysis of theory-of-mind development: the truth about false belief. Child Development, 72, 655-684. 


\section{Appendix}

\section{Additional Analyses}

Preliminary. Preliminary analyses were conducted to examine whether the arrangement of the containers $\left(\chi^{2}(5)=2.43, p=.79, \mathrm{~ns}\right)$ and multiple experimenters (ingroup: $\chi^{2}(5)=5.5, p$ $=.36$, ns $\&$ outgroup: $\chi^{2}(3)=2.27, p=.52 \mathrm{~ns}$ ) in each condition influenced children's searching behavior. Neither effect was significant. In addition, analyses were conducted to examine whether demographic factors, such as children's gender $\left(\chi^{2}(1)=.14, p=.14\right.$, ns $)$ religious background $\left(\chi^{2}(1)=.16, p=.16, \mathrm{~ns}\right)$ and location of residence $\left(\chi^{2}(1)=.94, p=.63\right)$ contributed to their searching patterns. Results were not significant, and thus these variables were not included in the main analyses reported here.

Memory Check Question. Removing children who failed to pass memory check questions would not influence the overall effect of condition. Overall 3-year-olds remained credulous more often in both groups, revealing no significance across conditions $\chi^{2}(1)=.06, p$ $=.81 \mathrm{~ns}$. In addition, the effect of condition remained significant for 4 -year-old children $\chi^{2}(1)=$ $5.92, p=.02$. In the outgroup condition, 4-year-olds were significantly more skeptical compared to 4-year-olds in the ingroup condition.

Logistic Regression for Children in the Ingroup Condition. A logistic regression was conducted to explore whether children's age in months and level of exposure to multiple ethnicities served as significant predictors of children's trust in the false testimony of ingroup speakers. See Table 4 for a description of the model. 
Table 4.

Logistic Regression with Age in Months and Exposure to Different Ethnicities as Predictors (Ingroup)

\begin{tabular}{lllll}
\hline & & & \multicolumn{2}{c}{$95 \%$ CI Odds Ratio } \\
Included & B (SE) & Lower & Odds Ratio & Upper \\
Constant & $12.89(26.43)$ & & & \\
Age in Months & $-.232(0.51)$ & .297 & .79 & 2.12 \\
Exposure & $-17.9(25.18)$ & .000 & .00 & 4.77 \\
Age x Exposure & $.32(0.47)$ & .54 & 1.37 & 3.46 \\
\hline
\end{tabular}
Note. Model $\chi^{2}(3)=3.33, p=34$, ns. 